Revista Destaques Acadêmicos, Lajeado, v. 13, n. 1, 2021. ISSN 2176-3070

DOI: http://dx.doi.org/10.22410/issn.2176-3070.v13i1a2021.2617

http://www.univates.br/revistas

\title{
A HOLDING FAMILIAR E AS SOCIEDADES EMPRESARIAIS DO MUNICÍPIO DE LAJEADO/RS: POSSÍVEL APLICAÇÃO E RESULTADOS
}

\author{
Júnior Roberto Willig ${ }^{1}$, Júlia Helena Vuaden Schmitz²
}

Resumo: As sociedades empresariais familiares possuem grande importância ao setor econômico, cultural e social do país, pois contribuem no desenvolvimento das sociedades mediante a geração de lucros, rendas e trabalhos. Contudo, há alta incidência de extinção das suas atividades, devido a diversos aspectos, como conflitos familiares e sucessórios. Observando-se isso, este estudo apresenta as possibilidades de uma holding familiar constituir-se como ferramenta sucessória e de blindagem patrimonial, bem como qual a implicação desse instituto nas sociedades empresariais atualmente no Município de Lajeado/RS. A presente pesquisa possui característica quali-quantitativa, realizada por meio do método dedutivo e de procedimentos bibliográfico, documental e estudo de caso. Procura-se demonstrar, inicialmente, o que vem a ser esse instituto, quais são seus aspectos, tal como seus benefícios ofertados aos empresários lajeadenses. Por fim, esta pesquisa demonstra os resultados obtidos com o estudo de caso realizado com empresários lajeadenses e sua respectiva análise. Conclui-se, portanto, que a holding familiar é um instrumento desconhecido pelos empresários lajeadenses, encontrandose, no município, negócios familiares sem qualquer proteção contra eventos futuros e imprevistos, podendo este instituto tornar-se em uma aliada ferramenta a eles, visto que proporciona diversos benefícios no campo patrimonial e sucessório, aspectos estes que merecem atenção por quem requer tranquilidade e longevidade aos seus negócios.

Palavras-chave: Holding familiar. Empresas familiares. Sucessão.

\section{INTRODUÇÃO}

Atualmente, há uma modalidade empresarial, em especial, que está em constante crescimento e desenvolvimento, sendo capaz de ofertar diversos benefícios aos cidadãos e região onde instalada, isso pois aumentam

1 Doutorando em Direito Público pelo Programa de Pós-Graduação em Direito (Mestrado e Doutorado) da UNISINOS (São Leopoldo/RS); Professor da área de Direito Empresarial na Universidade do Vale do Taquari - Univates (Lajeado/RS); e-mail jwillig@univates.br.

2 Graduanda do Curso de Direito da Universidade do Vale do Taquari - Univates. 
a empregabilidade e movimentam o crescimento da economia de sua região, contribuindo significativamente na melhoria da qualidade de vida de todos ao seu redor. Está-se diante das sociedades familiares, as quais encontram-se cada vez mais crescentes no país.

Destas sociedades empresariais, pode-se afirmar que grande parte enfrentam problemas familiares, já que constata-se que a grande maioria dos empresários lajeadenses acreditam haver dificuldades nos relacionamentos entre familiares que laboram em uma mesma empresa. Por tal motivo, muitos empreendedores e seus familiares não conseguem manter viva a sua sociedade, devido aos problemas pessoais que, na maioria das vezes, são levados para dentro do ambiente de trabalho. Adachi (2006), ao falar sobre a duração de uma sociedade familiar, afirma que ela não sobrevive mais do que três gerações, comparando essa situação ao ditado popular que diz pai rico, filho nobre e neto pobre.

Outra questão preocupante é a falta de planejamento sucessório. Kipper et al. (2016) em sua pesquisa sobre a sucessão em sociedades empresariais lajeadenses, constataram a existência de conflitos no momento sucessório nas sociedades empresariais do Município de Lajeado/RS, as quais encontraram dificuldades nas relações entre seus familiares, principalmente por parte do sucessor que supostamente estaria passando por momentos de pressão.

Diante de todo esse contexto negativo que envolve estas sociedades empresariais, já destacam os estudiosos Casillas, Díaz e Vázquez (2007) que as sociedades familiares possuem dificuldades em sua evolução, bem como são as que mais apresentam baixas expectativas de vida em comparação às sociedades de outros ramos, apresentando, como consequência, uma maior taxa de mortalidade.

Com base nessa situação, o presente estudo tem como objetivo verificar as possibilidades da holding familiar constituir-se como ferramenta sucessória e blindagem patrimonial, bem como qual é a sua implicação nas sociedades empresariais presentes no Município de Lajeado/RS, observando-se a sua influência para a contribuição ao bom desenvolvimento das empresas, tal como economia e geração de empregos em regiões próximas.

Dessa forma, o problema proposto para a presente pesquisa busca identificar quais as possibilidades da holding familiar constituir-se como ferramenta sucessória e blindagem patrimonial, bem como qual a implicação desse instituto no campo empresarial atualmente no Município de Lajeado? Como hipóteses ao problema proposto, insta-se apurar se este instituto realmente garante longevidade para uma sociedade familiarizada, já que seus benefícios visam a facilidade de administração e proteção dos bens do(s) sócio(s) e sociedade empresarial, ressaltando-se a importância da realização de um planejamento sucessório capaz de evitar uma longa disputa judicial a partir de inventários e partilhas sobre os bens, diminuindo, por si só, a probabilidade de extinção da empresa pela incapacidade e má gestão do sucessor. 


\section{PROCEDIMENTOS METODOLÓGICOS}

No que refere-se ao tipo de pesquisa, quanto ao modo de abordagem, no presente estudo caracteriza-se como quali-quantitativa. Segundo Goldenberg (2007), esse modo demonstra-lhe uma maior confiança com relação aos dados obtidos através da aplicação da pesquisa, bem como ele explana que não haverá situações particulares influenciando nos resultados finais dos pesquisadores.

Gerhardt e Silveira (2009) afirmam que a pesquisa qualitativa preocupase com o que um determinado grupo social compreende, deixando de lado dados e quantidades numéricas com relação a estes. Por sua vez, no que tange à pesquisa quantitativa, Mezzaroba e Monteiro (2014, p. 135) entendem que ela "[...] representa tudo aquilo que pode ser medido, o mensurável". Já para Fonseca (2002), os dados obtidos através da pesquisa quantitativa podem ser quantificados a fim de determinar-se uma situação que ocorre com todos os indivíduos que participaram do estudo.

Portanto, opta-se pela junção das pesquisas qualitativa e quantitativa, uma vez que a primeira embasará sobre conceitos aplicáveis encontrados na doutrina, enquanto a segunda forma preocupa-se com a quantidade de informações obtidas no estudo de caso.

Quanto à metodologia, para a realização da presente pesquisa e alcance dos objetivos almejados, utilizou-se o método dedutivo. Chemin (2015, p. 72) explica que o método dedutivo "[...] parte de argumentos gerais, como, por exemplo, de uma teoria de base, para chegar a argumentos/conclusões particulares".

Dessa forma, a pesquisa utilizará recursos doutrinários e legislativos para compreender-se o conceito, características e benefícios do instituto da holding familiar, bem como aproveitará um estudo de caso, o qual servirá para avaliar os conhecimentos dos empresários lajeadenses acerca do referido instituto e questões relacionadas aos problemas enfrentados pelas sociedades empresariais.

Por fim, o estudo de caso realizado na presente pesquisa consiste em um questionário elaborado no programa Google Forms, o qual compõe-se de dezoito perguntas relacionadas aos perfis dos empresários no território Lajeadense, aos problemas familiares, sucessórios, assim como sobre o instituto da holding e seus benefícios. Ressalta-se que não são utilizados tão pouco requisitados dados pessoais dos participantes e de terceiros, uma vez que apenas busca-se, com a aplicação do questionário, obter conhecimentos sobre o tema na realidade na qual vive-se.

Logo, enviou-se este questionário aos empresários localizados no Município de Lajeado/RS através de seus respectivos endereços eletrônicos obtidos em seus websites, os quais podem ser acessados livremente por qualquer pessoa. Ressalta-se que o questionário ficou disponível para resolução das 
questões pelo período de nove dias (de 07 de outubro de 2019 a 15 de outubro de 2019), sendo respondido por 27 (vinte e sete) empresários.

Ao final, a partir da obtenção dos resultados, realiza-se uma análise conjunta destes com doutrina, com o objetivo de embasar-se os entendimentos obtidos, gerando-se maior ênfase às respostas dos participantes.

Portanto, a presente pesquisa busca compreender e apresentar o conceito e benefícios ofertados pela holding familiar nas mais diversas sociedades familiarizadas estabelecidas no Município de Lajeado/RS.

\section{HOLDING COMO REMÉDIO PRESCRITO PARA GARANTIR LONGEVIDADE ÀS SOCIEDADES EMPRESARIAIS FAMILIARIZADAS}

Holding, ou também chamada de Holding Companies, passou a existir no final do século XIX em alguns países da Europa quando do acelerado desenvolvimento das indústrias e grande concentração de capital a alguns empresários daquela região. Estes, por sua vez, possuíam mais vantagens do que em comparação aos pequenos empresários, os quais não conseguiam manter suas empresas ativas diante da competitividade com aquelas e, como solução, tiveram que incorporar suas empresas às empresas de grande porte, resultando na junção de empresas que detinham grande monopólio industrial (LEOBLEIN, 2017).

No Brasil, há divergência doutrinária sobre o tema, sendo difícil afirmar um contexto histórico para o surgimento das holdings no país, pois os empresários brasileiros as criavam com o objetivo de atuar com empreendimentos de serviços (OLIVEIRA, 2003). Contudo, diz-se que com o advento no ordenamento jurídico brasileiro da Lei n. ${ }^{\circ} 6.404$ de 1976, conhecida popularmente como Lei das Sociedades Anônimas, surgiu o instituto da holding. $\mathrm{O}$ artigo $2^{\circ}$, parágrafo $3^{\circ}$, desta norma, explica que a holding conceitua-se em uma sociedade que participa em outra sociedade com o objetivo de realizar seu objeto social, bem como angariar-se de benefícios e incentivos fiscais.

Sopesando as diversas opiniões doutrinárias acerca do assunto, entende-se que este instituto serve para garantir a continuidade das sociedades empresariais, bem como facilitar o seu planejamento, organização, controle e processo diretivo, propiciando ao sócio o benefício de organizar a sua sociedade quando em vida, ao escolher quem irá liderá-la e de qual maneira restará preservado o seu patrimônio e o da sociedade após seu falecimento (OLIVEIRA, 2003).

Em consonância a isso, Lodi (1982) expõe que a holding não exerce atividades de produção ou circulação de bens, uma vez que estes não são seus objetivos, pois apenas realiza o monitoramento e regula as funções de planejamento e controle de grupo presentes nas sociedades empresariais para a sua continuidade sadia no mercado societário. 
Holding, como gênero, possui diversas espécies e, dentre elas, encontrase a holding familiar, relevante para o presente estudo. Assim, importa-nos desbravar apenas os benefícios oferecidos pela holding familiar.

Mamede e Mamede (2018) observam que a característica principal desta espécie é enquadrar-se em espaços familiares e obter desafios com relação à organização do patrimônio desses, bem como a administração de seus bens e sucessão hereditária. Outras são as parecidas palavras de Mariano (2019a, texto digital), o qual aprecia que a holding "trata-se de um instrumento que tem como consequência a redução de tributos, a blindagem do patrimônio e o planejamento sucessório".

Por ser um instrumento que tem por finalidade planejar e controlar outra sociedade familiarizada, a holding familiar é uma ferramenta eficaz para quem busca calmaria em seus negócios. Existem diversas sociedades familiares espalhadas em todo o mundo e para garantir o bom gerenciamento delas, é necessário haver tranquilidade por parte de seus integrantes (LODI; LODI, 2011).

Silva e Rossi (2017) dizem que a holding familiar pode ser criada com a intenção de controlar as atividades quotas das ações em sociedades familiares, podendo, aliás, concentrar todas as atividades empresariais em uma só sociedade, objetivando, ainda, adotar planos sucessórios e tributários para melhor solução dos conflitos. Por fim, cita este autor outro benefício deste instituto, referente à proteção do patrimônio empresarial e do sócio, devido ao cuidado com contratos de compra, venda e aluguéis.

Percebe-se suas vantagens em amplos aspectos e entre eles encontramse os benefícios referentes à proteção patrimonial e a sucessão. Com relação ao primeiro benefício, conforme explica Pinto (2019, texto digital), este "é um conjunto de boas práticas que tem o propósito de cuidar, de forma adequada e visando o crescimento, dos bens materiais e imateriais, seja de uma empresa, de um indivíduo ou de uma família inteira por gerações".

O planejamento patrimonial adota cuidados inerentes aos conjuntos de bens que podem vir a serem afetados por problemas futuros da sociedade. Frisa-se que a realização de um planejamento patrimonial é benéfico porque traz segurança, estabilidade e garante um futuro com maior conforto aos empresários e membros de suas sociedades (CONHEÇA..., 2017).

Outro é o planejamento sucessório, diferente benesse dessa ferramenta. Silva e Rossi (2017) garantem a sua essencialidade quando da proteção aos bens da família, devido a opção que possuem as partes de proteger o patrimônio de acontecimentos inusitados e imprevistos, citando como exemplos o divórcio e a briga dos herdeiros pelos bens. Por sua vez, Mariano (2019b, texto digital) explica que o planejamento sucessório serve para definir "a sucessão do patrimônio, evitando conflitos de interesses familiares, principalmente após o falecimento dos titulares". 
Em seu entendimento, Casillas, Vázquez e Díaz (2007) afirmam que o planejamento sucessório trata-se de uma maneira impositiva e eficiente de formular vários documentos que transmitem a obrigação de transferir os bens e a sociedade das mãos do dono para as mãos dos seu sucessor, devendo-se iniciar o planejamento sucessório a partir do momento em que a sociedade apresente bases sólidas e boas condições de sobrevivência no futuro.

Silva e Rossi (2017) classificam algumas vantagens desse planejamento, como a proteção dos bens contra atitudes de terceiros; a escolha do herdeiro mais capacitado para continuar os negócios; o planejamento da forma de pagamento dos custos sucessórios; o desaparecimento de conflitos sucessórios; os gastos com inventários, bem como a desnecessidade de realizar a venda de um bem móvel ou imóvel com o objetivo de pagar uma dívida de impostos ou processos judiciais.

Propicia-se ao dirigente de uma sociedade empresarial com a realização de um planejamento sucessório, a possibilidade de realizar a sucessão em vida ou pós-morte, conforme expõe Donadel (2011). Explica o autor que a sucessão realizada em vida ocorre com a profissionalização dos sucessores. Outra escolha que o sucedido pode optar é a de que, se ele não quiser colocar familiares em seu posto por sentir-se inseguro, poderá realizar a sucessão profissional, mediante a escolha de um profissional capacitado e capaz de administrar uma sociedade, lembrando de que este último não é membro familiar do sucedido.

Diante de tudo o que já fora sido explanado até aqui sobre o planejamento patrimonial e sucessório, percebe-se que esses aspectos são pontos positivos e necessários que devem ser levados em consideração por aqueles empresários que desejam a continuidade de seus negócios. Não discute-se sobre a continuidade da sociedade por vários anos e nem pode-se determinar uma data padrão ou limite para isso, mas diz-se sobre a ativação das sociedades por longos períodos a fim de proporcionar rendas, trabalhos e lucros à economia, gerando bem-estar social a todos os cidadãos que delas tanto necessitam.

Conforme entendimento majoritário da doutrina, é comum que os empresários constituam suas holdings na forma de sociedades anônimas ou limitadas. Sobre a sociedade anônima, Lodi e Lodi (1987) afirmam que a holding pode ser fundada tanto em sociedades anônimas com capital aberto ou fechado.

Diante disso, esse autor recomenda que criar uma holding em uma sociedade anônima com capital aberto sirva para modelos de holdings administrativas, grandes sociedades e operadoras, as que possuem captação de recursos de terceiros e tenham imposições legais, objetivando maior transparência da gestão, grande chance de captação de recursos por meio de terceiros, a realização de testamento do seu sucessor, bem como o maior poder de negócio que o sócio pode obter e no menor investimento para controle (LODI; LODI, 1987). 
Com relação à criação das holdings em sociedades anônimas cujo capital for fechado, Lodi e Lodi (1987) recomendam sua realização para pequenos grupos empresariais, acionistas familiares, numerosos acionistas e holdings administrativas, cujos benefícios concentram-se no menor investimento em controles, maior representação institucional, mais controle na entrada de pessoas estranhas à sociedade e a determinação testamentária de um sucessor.

Ao contrário, há doutrinadores que apontam como melhor decisão a escolha pelo modelo da sociedade limitada. Para sustentar esse pensamento, sustentam que esta é, na teoria, a melhor opção por impedir que estranhos à sociedade ingressam nesta quando instituída a holding familiar (TEIXEIRA, J. A., 2012). Sobre este tipo societário, Donadel (2011, p. 18) afirma ser “[...] um tipo de sociedade cujo capital social é dividido em quotas, sendo que a responsabilidade de cada sócio se limita a sua devida quantidade de quotas subscritas e integralizadas no capital social".

Entretanto, apesar de haver discussões em torno destas duas formas societárias, há quem diga que a holding não é um tipo societário, podendo, dessa forma, revestir-se na forma de qualquer tipo societário previsto na legislação, como Mamede e Mamede (2018) que acreditam que as EIRELIS também podem ser controladas por uma holding. Igualmente, Baumgarten (2017) explica que a EIRELI é uma sociedade unipessoal que pode ter qualquer tipo de objeto lícito, sendo controlada pelas regras das sociedades limitadas, ainda que tenha um único sócio titular, bem como esta sociedade pode ser detentora de quotas e ações de outras sociedades, nada a impedindo para tal.

Porém, independentemente do tipo societário escolhido para criar essa ferramenta, a formação da holding possui tamanha necessidade para a continuidade dos negócios, pois "quando se tem um bom planejamento a holding se constitui numa importante ferramenta para a administração do patrimônio. Neste cenário surgem as vantagens e desvantagens, mas que em geral as vantagens se sobrepõem às desvantagens", conforme Donadel (2011, p. 56).

\section{MUNICÍPIO DE LAJEADO/RS E HOLDING FAMILIAR: CONSIDERAÇÕES INICIAIS}

Verifica-se que a região do Vale do Taquari sempre foi vista como uma terra fértil por quem nela passou. Repara-se que esta região dispõe de fáceis acessos a outras localidades do estado do Rio Grande do Sul ou outros estados, países e locais exteriores devido aos acessos por rodovias pavimentadas, locomoções por barcos, navios e balsas, assim como caminhos ferroviários e rodoviários, significando no bom desenvolvimento da região. Acrescenta-se, com base em pesquisa realizada pela Fundação de Economia e Estatística FEE/RS no ano de 2015, com ano base 2013, que o Produto Interno Bruto - 
PIB obtido nessa região alcança a margem dos $R \$ 10.064$ bilhões de reais $(\mathrm{O}$ VALE..., 2018).

Nota-se que essa evolução deu-se com o alto índice de indústrias e comércios que instalaram-se no local. As sociedades empresariais oferecem muitos benefícios ao Vale, gerando rendas e empregos à população. Acerca disso, Bencke e Silva (2016) ressaltam que as áreas do comércio e serviços geram maiores índices de empregabilidade nesta região.

Na mesma perspectiva de desenvolvimento, encontra-se o Município de Lajeado. Hickmann (2017) aponta que o município de Lajeado encontra-se bem desenvolvido devido à sua economia diferenciada, destacando-se, ainda, as sociedades empresariais presentes nos setores da indústria de alimentos e bebidas, agroindústrias, móveis e esquadrias, além dos demais setores encontrados nas áreas do comércio e serviços.

Quanto a isso, a composição do mercado econômico por setor e porte das sociedades mediante a quantidade de funcionários empregados nestas, conforme pesquisa realizada no ano de 2017 em Lajeado pelo SEBRAE, possui alto índice nas áreas relativas ao comércio e serviços, este último apontando um índice maior com relação ao outro. De igual forma, percebe-se que as sociedades predominantes na localidade são as micro e pequenas empresas, novamente com maiores índices nas prestadoras de serviços (PERFIL DAS CIDADES..., 2019).

Devido a esses aspectos, realizou-se no presente estudo questionamentos para definir o perfil predominante dos empresários do Município de Lajeado, no Vale do Taquari/RS, através da ferramenta Google Forms, enviado aos participantes através de seus endereços eletrônicos, obtidos mediante pesquisa manual em seus sites. Tais questionamentos versaram sobre o tipo societário, o setor de atividade, o porte e média de funcionários empregados, assim como há quantos anos a sociedade encontra-se ativa no mercado. Igualmente, questionou-se sobre situações envolvendo relações entre familiares que laboram em uma mesma sociedade, realização de planejamentos sucessório e sobre os aspectos e benefícios do instituto da holding e uma de suas modalidades, a holding familiar.

\section{HOLDING FAMILIAR E SUA APLICAÇÃO NAS SOCIEDADES EMPRESARIAIS FAMILIARIZADAS NO MUNICÍPIO DE LAJEADO: ANÁLISE DOS RESULTADOS}

No que refere-se ao tipo societário escolhido, constata-se que a grande maioria dos participantes, cerca de $85,2 \%$ dos respondentes, optaram por criar seus negócios na forma de sociedades limitadas.

Diniz (2014) caracteriza esse tipo societário como sendo o mais comum atualmente no país entre as sociedades simples e empresárias, chamando-se a atenção pela responsabilidade distribuída aos sócios. A autora comenta, ainda, 
que esse tipo societário classifica-se em uma sociedade contratual sui generis e híbrida, dispondo-se de cunhos capitalistas com relação à formação de sua estrutura orgânica e composta de normas cuja feição mostra-se personalística nas relações dos sócios entre si.

Analisa-se, também, que três respondentes definiram-se como empresários individuais e únicos sócios, totalizando-se cada uma destas respostas cerca de 3,7\%. Torna-se oportuno ressaltar que a holding pode ser criada com a intenção de cuidar destas sociedades tanto quanto das sociedades limitadas, pois há doutrinadores ressaltando que esse instituto pode revestir-se em qualquer forma societária prevista na legislação.

No que relaciona-se ao setor de atividade na qual a sociedade empresarial atua, constata-se que $48,1 \%$ dos entrevistados prestam suas atividades no setor de serviços; $33,3 \%$ ao comércio e 18,5\% ligam-se ao setor da indústria. Essas características aumentam o bom desenvolvimento do município, conforme depreende-se do entendimento de Hickmann (2017).

Ressalta-se que a holding não pode ser criada com o intuito de oferecer esses serviços, porém, pode vir a constituir-se para proteger e prestar maior segurança à essas sociedades, conforme denota-se do entendimento de Lodi (1982).

Quanto ao porte das sociedades participantes na pesquisa, verificase que a maioria dos empresários participantes na pesquisa possuem até 15 (quinze) funcionários devidamente empregados em suas sociedades, assim como realizam suas atividades pelo período de 15 e 25 anos, correspondendo ao montante de $22,2 \%$ das respostas.

Torna-se importante ressaltar a importância dessas sociedades ao mercado societário e campo econômico com a geração de lucros, rendas e empregos a todos os cidadãos. No Município de Lajeado a situação é favorável, percebendo-se seus benefícios e gradativos aumentos nas sociedades ligadas aos setores da indústria e comércio entre os anos de 2006 até 2016 (PERFIL DAS CIDADES..., 2019).

Para obter-se uma maior duração das sociedades no mercado, recomenda-se a utilização da holding para oferecer um melhor equilíbrio diante das crises setoriais (LODI; LODI, 1987). Na mesma linha de raciocínio, Silva e Rossi (2017) alegam que a holding presta-se para firmar o domínio econômico de um grupo empresarial através da aplicação de um exercício de controle centralizado que possibilite aos empresários a unificação de suas gestões estratégicas, abordando-se aquelas ligadas às decisões financeiras, operacionais, marketing e diversas outras questões.

Também, contempla-se com a pesquisa que todos os sócios quotistas ou acionistas controladores fundadores da sociedade ainda exercem o cargo de direção da mesma, conforme $66,7 \%$ das respostas; de outra maneira, percebe- 
se que apenas $33,3 \%$ destes não mais realizam seus postos de dirigentes da sociedade.

Sobre isso, Leone (2005) afirma que o momento da sucessão caracterizase por gerar conflitos entre os dirigentes da sociedade, devendo-se atentar cautelosamente aos seus cuidados. Afirma, igualmente, que dentre diversos problemas que podem ser encontrados nesse momento, presencia-se aqueles referentes à transmissão do poder, a dificuldade no encontro de um membro familiar ou profissional sem laço afetivo para ocupação do cargo e a devida profissionalização destes, assim como problemas ligados às incorporações, fusões, cisões e vendas de patrimônios construídos por décadas.

Quanto à presença de familiares laborando nas empresas, constatase que a maioria, cerca de $33,4 \%$ dos empresários participantes da pesquisa, responderam que não há familiares trabalhando em sua sociedade; seguindo-se por aproximadamente 20,8\% que responderam que seus filhos laboram; 20,8\% cônjuges; $4,2 \%$ sobrinhos; $4,2 \%$ irmãos; $4,2 \%$ que há um filho de um sócio; $4,2 \%$ responderam que há cônjuge, filhos e sobrinhos; $4,2 \%$ que encontram-se em sua sociedade marido e esposa como sócios e colegas de trabalho; $4,2 \%$ que há cunhados.

No entanto, ao analisar-se os dados, verifica-se uma realidade positiva com relação a estes, uma vez que encontram-se negócios familiares na região. Quanto a isso, Frugis (2007) destaca que as sociedades familiares caracterizamse em parcelas significativas entre os grupos empresariais no país, possuindo grande importância para a economia.

Quanto a presença desses familiares e suas relações nas sociedades, analisa-se que $76,9 \%$ dos participantes responderam que acreditam que há problemas nas relações entre familiares que trabalham em uma mesma empresa, ao passo que apenas $23,1 \%$ dos participantes acreditam que não.

Isso vai de encontro com o que fora descoberto por Kipper et al. (2016) em sua pesquisa sobre a sucessão em sociedades empresariais lajeadenses. Conforme esses autores, constatou-se a existência de conflitos no momento sucessório nas sociedades empresariais do município. Frisam esses autores que, após a passagem da sucessão, a situação acalmou-se e os herdeiros amadureceram, atitude na qual resultou no desaparecimento de forma natural dos conflitos percebidos.

Estes fatos também correlatam-se com o pensamento de alguns doutrinadores, como Oliveira (2006) que destaca algumas peculiaridades das sociedades familiares e, dentre elas, encontra-se presente a dificuldade em separar-se o que é emocional do que é racional nas suas relações. Este autor cita, ainda, diversos conflitos que podem ocorrer em sociedades familiarizadas, desencadeados, na maioria das vezes, pelo próprio fundador da sociedade e até mesmo por seus parentes, como irmãos, primos e outros descendentes. 
Por sua vez, Ricca (2007) salienta que em uma estrutura familiar busca-se a satisfação pessoal de cada um de seus membros, enquanto que na sociedade empresarial busca-se atingir metas relacionadas ao mercado e obtenção de lucros. Refere-se, ainda, que a estrutura familiar possui em seu corpo rivalidades, diferenças pessoais que podem relacionar-se às gerações e condições sexuais, resultando-se na formação de grupos rivais dentro da família.

Quanto ao planejamento sucessório, percebe-se que 51,9\% dos participantes afirmam que não possuem planejamento sucessório para sua empresa, mas que já pensaram sobre o assunto; seguido de $33,3 \%$ que afirmam que não possuem e apenas $14,8 \%$ declaram que já possuem algum planejamento sucessório.

Passos et al. (2006) ressaltam que muitos empresários associam a realização da sucessão com o medo pela mudança. Por seu turno, Leone (2005) destaca a importância da sucessão em qualquer modalidade de sociedade, não somente nas familiares. Para ele, as chances que a sociedade possui para sobreviver descansa na sucessão planejada e nas regras criadas para regular a convivência da sociedade empresarial e as relações entre familiares.

Silva e Rossi (2017) frisam que pensar o quanto antes em planejar um bom plano sucessório assemelha-se a uma chave para o sucesso, pois de forma antecipada irá informar ao sucedido quais as atitudes devem ser adotadas em determinados momentos que ocorrerão no futuro.

Daqueles participantes que referiram possuir planejamento sucessório para sua sociedade empresarial, constata-se que $78,6 \%$ dos respondentes possuem um contrato sucessório informal, não dispondo de cláusulas com normas e regras escritas para situações futuras que possam vir a acometer a sociedade, enquanto que $21,4 \%$ dos respondentes possuem um contrato sucessório que dispõe em sua estrutura de cláusulas claras e acessíveis a todos os integrantes da sociedade.

E quanto a sua forma e escolha, percebe-se que a maioria dos empresários, cerca de $56 \%$ pretendem realizar a sucessão familiar, quando da escolha de algum membro familiar para ocupação de seu cargo, enquanto que apenas $44 \%$ dos participantes optaram pela sucessão profissional, quando da escolha de um profissional que labore há muito tempo na sociedade e que não possua nenhum laço sanguíneo consigo.

Diante disso, já é de notar-se nos noticiários que diversas sociedades empresariais instaladas na região lajeadense começaram a intensificar o papel da sucessão em suas companhias. Com isso, percebe-se que os empresários estão preocupando-se com o futuro de seus negócios e de seus integrantes, inclusive daqueles que fazem parte das suas lutas diárias.

Frisa-se novamente o estudo realizado por Kipper et al. (2016) sobre processo sucessório de sociedades do Município de Lajeado/RS. Diante de suas 
perspectivas, explicitam esses autores que o processo sucessório que encontrase em andamento nas sociedades empresariais verificadas possui uma forma tranquila por parte dos sucedidos e sucessores.

Por fim, apesar de haver grande discussão doutrinária em torno do assunto, analisa-se que a holding ainda é um mecanismo pouco conhecido pelos empresários lajeadenses, entretanto, positivamente, estes pretendem conhecer de forma mais aprofundada o referido instituto.

\section{CONCLUSÃO}

O objetivo do presente estudo consiste em analisar as possibilidades de aplicar o instituto da holding familiar nas sociedades empresariais familiares estabelecidas no Município de Lajeado/RS.

Para buscar essa compreensão, o presente artigo preocupou-se, em um primeiro momento, em estabelecer o que é uma holding familiar, desde o seu surgimento até seus benefícios mais importantes aos empresários, sendo, portanto, os planejamentos patrimoniais e sucessórios. Em seguida, demonstrou-se as características do Município de Lajeado e Região do Vale do Taquari, região onde localiza-se o referido município, a fim de compreender quais são os perfis dos empresários e suas respectivas sociedades empresariais ativas, para melhor compreensão da aplicação da espécie holding familiar e consequente benefícios advindos de seu uso.

Logo após, apresentou-se os dados obtidos com a aplicação de um questionário enviado aos empresários lajeadenses, onde constatou-se existirem, no município pesquisado, a presença de diversos negócios familiares, assim como a dificuldade na relação entre os familiares que laboram em uma mesma empresa. Além disso, importante destaque deu-se com a informação obtida acerca da realização ou não de planejamento sucessório que define objetivos e soluções a longo prazo. Quanto a isso, observou-se que a grande maioria dos participantes não realizaram qualquer forma de planejamento sucessório para a sua sociedade empresarial. Por fim, obteve-se a informação de que a grande maioria dos empresários lajeadenses não possuem conhecimentos acerca do referido instituto. Diante disso, constatou-se, positivamente, que muitos destes afirmaram que possuem a vontade de aprofundar seus conhecimentos sobre a holding familiar.

Dessa forma, analisando-se o problema proposto para a presente pesquisa - quais as possibilidades da holding familiar constituir-se como ferramenta sucessória e blindagem patrimonial, bem como qual a implicação desse instituto no campo empresarial atualmente no Município de Lajeado? conclui-se que as hipóteses levantadas são verdadeiras, uma vez que a holding familiar proporciona um maior controle e cuidado às sociedades na qual presta seus trabalhos, facilitando a tomada de atitudes em momentos desagradáveis e organizando a relação entre familiares que trabalham na mesma sociedade. 
Ainda, ressalta-se que esse instituto preocupa-se em realizar planejamentos antecipados para realizar problemas futuros, os quais podem caracterizarse em planejamentos patrimoniais e sucessórios, o que contribui também na facilidade de administração e cuidado dos patrimônios, além da sucessão de cargos entre familiares e a facilidade na transmissão de bens com a herança.

Assim, diante dos benefícios ofertados por essa espécie e acerca dos aspectos apresentados neste estudo, verifica-se que este instituto contribui de forma positiva na longevidade das sociedades empresariais e diminui a probabilidade de extinção destas, fazendo-se da holding familiar um mecanismo de proteção eficaz e blindado contra problemas futuros que poderão impactar a continuidade sadia das sociedades lajeadenses no mercado.

\section{REFERÊNCIAS}

ADACHI, Pedro Podboi. Família S.A.: Gestão de Empresa Familiar e Solução de Conflitos. São Paulo: Atlas, 2006.

BAUMGARTEN, Carlos. Uma Eireli pode ser uma Holding? BCO Empresas Patrimoniais, 27 set. 2017. Disponível em: <http:/ /empresaspatrimoniais.com. br/2017/09/27/uma-eireli-pode-ser-uma-holding/ >. Acesso em: 03 set. 2019.

BRASIL. Lei n. ${ }^{\circ}$ 6.404, de 15 de dezembro de 1976. Dispõe sobre as sociedades por ações. Brasília, DF, dez 1976. Disponível em: <http:/ / www.planalto.gov.br/ccivil_03/ Leis/L6404compilada.htm>. Acesso em: 05 ago. 2019.

CASILLAS BUENO, José Carlos; DÍAZ FERNÁNDEZ, Carmen; SÁNCHEZ VÁZQUEZ, Adolfo. Gestão da empresa familiar: conceitos, casos e soluções. São Paulo: Thomson, 2007.

CHEMIN, Beatris F. Manual da Univates para trabalhos acadêmicos: planejamento, elaboração e apresentação. 3. ed. Lajeado: Univates, 2015. E-book. Disponível em: <http://www.univates.br/biblioteca>. Acesso em: 28 out. 2019.

CONHEÇA a relação entre planejamento sucessório e proteção patrimonial. Grupo Fatos, São Paulo, 2017. Disponível em: <https://blog.grupofatos.com.br/conheca-arelacao-entre-planejamento-sucessorio-e-protecao-patrimonial/>. Acesso em: 02 set. 2019.

DINIZ, Maria Helena. Curso de Direito Civil Brasileiro: 8. Direito de Empresa. 6. ed. São Paulo: Saraiva, 2014.

DONADEL, Rafael. Vantagens e desvantagens de uma holding no processo sucessório de uma empresa familiar. 2011. 62 f. Monografia (Especialização em Ciências Contábeis) - Universidade do Extremo Sul Catarinense - UNESC, Criciúma, jul. 2011. Disponível em: <http://repositorio.unesc.net/bitstream/1/548/1/ Rafael\%20Donadel\%20.pdf>. Acesso em: 12 ago. 2019. 
FONSECA, João José Saraiva da. Metodologia da pesquisa científica. Fortaleza: UEC, 2002.

FRUGIS, Leonardo Ferretti. As empresas familiares e a continuidade na gestão das terceiras gerações. São Paulo: EDUC; Fapesp, 2007.

GERHARDT, Tatiana Engel; SILVEIRA, Denise Tolfo. Métodos de pesquisa: coordenado pela Universidade Aberta do Brasil - UAB/UFRGS e pelo Curso de Graduação Tecnológica - Planejamento e Gestão para o Desenvolvimento Rural da SEAD/UFRGS. Porto Alegre: Editora da UFRGS, 2009. Disponível em: <http://www. ufrgs.br/cursopgdr/downloadsSerie/derad005.pdf>. Acesso em: 05 out. 2019.

GOLDENBERG, Mirian. A arte de pesquisar: como fazer pesquisa qualitativa em ciências sociais. 10. ed. Rio de Janeiro: Record, 2007.

HICKMANN, Larissa Maria. Liderança em empresas familiares e não familiares. 2017. 72 f. Monografia (Graduação em Administração - LFE Comércio Exterior) Universidade do Vale do Taquari - Univates, Lajeado, 22 jun. 2017. Disponível em: <http:/ / hdl.handle.net/10737/1762>. Acesso em: 05 out. 2019.

KIPPER, Tobias Ely et al. Sugestões para o processo sucessório de uma empresa familiar localizada na cidade de Lajeado/RS. Univates, Revista Destaques Acadêmicos. Lajeado, v. 8, n. 1, 2016. Disponível em: <http:/ / univates.br/revistas/ index.php/destaques/article/view/523>. Acesso em: 18 out. 2019.

LEOBLEIN, Tiago. A holding familiar como instrumento de proteção patrimonial e planejamento sucessório e tributário. 2017. 68 f. Monografia (Especialização em Direito) - Universidade Federal de Santa Maria, Santa Maria, 12 dez. 2017. Disponível em: <http:/ / repositorio.ufsm.br/handle/1/12640>. Acesso em: 24 ago. 2019.

LEONE, Nilda Maria de Clodoaldo Pinto Guerra. Sucessão na empresa familiar: preparando as mudanças para garantir sobrevivência no mercado globalizado. São Paulo: Atlas, 2005.

LODI, João Bosco. Lobby \& Holding: as bases do poder. São Paulo: Pioneira, 1982.

LODI, João Bosco; LODI, Edna Pires. Holding. 2. ed. ver. ampl. E atual. São Paulo: Pioneira, 1987. 186 p.

. Holding. 4. ed. rev. e atual. São Paulo: Cengage Learning, 2011. E-book. Disponível em: <http:/ / www.univates.br/biblioteca>. Acesso em: 01 set. 2019.

MAMEDE, Gladston; MAMEDE, Eduarda Cotta. Holding Familiar e Suas Vantagens: planejamento jurídico e econômico do patrimônio e da sucessão familiar. 10. ed. rev. e atual. São Paulo: Atlas, 2018. E-book. Disponível em: <http:/ / www.univates.br/ biblioteca>. Acesso em: 01 set. 2019. 
MARIANO, Mayara. Holding patrimonial e o planejamento tributário. O Debate, 28 ago. 2019a. Disponível em: <https:/ / www.odebate.com.br/mundo-empresarial/ holding-patrimonial-e-o-planejamento-tributario.html>. Acesso em: 05 set. 2019.

MEZZAROBA, Orides; MONTEIRO, Cláudia S. Manual de metodologia da pesquisa no Direito. 6. ed. São Paulo: Saraiva, 2014.

OLIVEIRA, Djalma de Pinho Rebouças de. Holding, administração corporativa e unidade estratégica de negócio: uma abordagem prática. 3. ed. ver. ampl. São Paulo: Atlas, 2003.

Empresa Familiar: como fortalecer o empreendimento e otimizar o processo sucessório. 2. ed. São Paulo: Atlas, 2006.

O VALE do taquari. CIC Vale do Taquari, 17 abr. 2018. Disponível em: <http:/ / www.cicvaledotaquari.com.br/cic-vt/o-vale-do-taquari/>. Acesso em: 28 set. 2019.

PASSOS, Édio et al. Família, família, negócios à parte: como fortalecer laços e desatar nós na empresa familiar. 5. ed. São Paulo: Editora Gente, 2006.

PERFIL das cidades gaúchas: Lajeado 2019. SEBRAE, 2019. Disponível em: <http:/ / datasebrae.com.br/municipios/rs/Perfil_Cidades_Gauchas-Lajeado.pdf $>$. Acesso em: 29 set. 2019.

PINTO, Leonardo. Como fazer um bom planejamento patrimonial e sucessório. Genial Investimentos, 09 jul. 2019. Disponível em: <https:/ /blog. genialinvestimentos.com.br/planejamento-patrimonial/>. Acesso em: 02 set. 2019.

RICCA, Domingos. Sucessão na Empresa Familiar: conflitos e soluções. São Paulo: Editora CLA, 2007.

SILVA, Fabio Pereira da; ROSSI, Alexandre. Holding Familiar: visão jurídica do planejamento societário, sucessório e tributário. 2. ed. São Paulo: Trevisan Editora, 2017. E-book. Disponível em: <http:/ / www.univates.br/biblioteca>. Acesso em: 22 set. 2019.

TEIXEIRA, João Alberto. Holding Familiar: tipo societário e seu regime de tributação. Contábeis, 31 ago. 2012. Disponível em: <https:/ / www.contabeis.com.br/ $\operatorname{artigos} / 893 /$ holding-familiar-tipo-societario-e-seu-regime-de-tributacao/>. Acesso em: 27 ago. 2019. 